University of Nebraska - Lincoln

DigitalCommons@University of Nebraska - Lincoln

3-1-2005

Confirmatory and Quantitative Analysis of $\boldsymbol{\beta}$-Lactam Antibiotics in Bovine Kidney Tissue by Dispersive Solid-Phase Extraction and Liquid Chromatography-Tandem Mass Spectrometry

\author{
Clifton K. Fagerquist \\ USDA-ARS, cfagerquist@pw.usda.gov \\ Alan R. Lightfield \\ USDA-ARS, alan.lightfield@ars.usda.gov \\ Steven J. Lehotay \\ USDA-ARS, Steven.Lehotay@ars.usda.gov
}

Follow this and additional works at: https://digitalcommons.unl.edu/usdaarsfacpub

Fagerquist, Clifton K.; Lightfield, Alan R.; and Lehotay, Steven J., "Confirmatory and Quantitative Analysis of $\beta$-Lactam Antibiotics in Bovine Kidney Tissue by Dispersive Solid-Phase Extraction and Liquid Chromatography-Tandem Mass Spectrometry" (2005). Publications from USDA-ARS / UNL Faculty. 1763. https://digitalcommons.unl.edu/usdaarsfacpub/1763

This Article is brought to you for free and open access by the U.S. Department of Agriculture: Agricultural Research Service, Lincoln, Nebraska at DigitalCommons@University of Nebraska - Lincoln. It has been accepted for inclusion in Publications from USDA-ARS / UNL Faculty by an authorized administrator of DigitalCommons@University of Nebraska - Lincoln. 


\title{
Confirmatory and Quantitative Analysis of $\beta$-Lactam Antibiotics in Bovine Kidney Tissue by Dispersive Solid-Phase Extraction and Liquid Chromatography-Tandem Mass Spectrometry
}

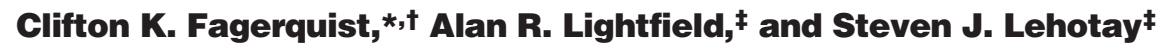 \\ Western Regional Research Center, Agricultural Research Service, U.S. Department of Agriculture, \\ Albany, California 94710, and Eastern Regional Research Center, Agricultural Research Service, \\ U.S. Department of Agriculture, Wyndmoor, Pennsylvania 19038
}

A simple, rapid, rugged, sensitive, and specific method for the confirmation and quantitation of $10 \beta$-lactam antibiotics in fortified and incurred bovine kidney tissue has been developed. The method uses a simple solvent extraction, dispersive solid-phase extraction (dispersiveSPE) cleanup, and liquid chromatography-tandem mass spectrometry (LC/MS/MS) for confirmation and quantitation. Dispersive-SPE greatly simplifies and accelerates sample cleanup and improves overall recoveries compared with conventional SPE cleanup. The $\beta$-lactam antibiotics tested were as follows: deacetylcephapirin (an antimicrobial metabolite of cephapirin), amoxicillin, desfuroylceftiofur cysteine disulfide (DCCD, an antimicrobial metabolite of ceftiofur), ampicillin, cefazolin, penicillin G, oxacillin, cloxacillin, naficillin, and dicloxacillin. Average recoveries of fortified samples were $\mathbf{7 0} \%$ or better for all $\beta$-lactams except DCCD, which had an average recovery of $58 \%$. The $\mathrm{LC} / \mathrm{MS} / \mathrm{MS}$ method was able to demonstrate quantitative recoveries at established tolerance levels and provide confirmatory data for unambiguous analyte identification. The method was also tested on 30 incurred bovine kidney samples obtained from the USDA Food Safety and Inspection Service, which had previously tested the samples using the approved semiquantitative microbial assay. The results from the quantitative LC/MS/MS analysis were in general agreement with the microbial assay for 23 samples although the LC/MS/MS method was superior in that it could specifically identify which $\beta$-lactam was present and quantitate its concentration, whereas the microbial assay could only identify the type of $\beta$-lactam present and report a concentration with respect to the microbial inhibition of a penicillin $G$ standard. In addition, for 6 of the 23 samples, LC/MS/ MS analysis detected a penicillin and a cephalosporin $\beta$-lactam, whereas the microbial assay detected only a penicillin $\beta$-lactam. For samples that do not fall into the "general agreement" category, the most serious discrepancy involves two samples where the LC/MS/MS method detected a violative level of a cephalosporin $\beta$-lactam (deacetylcephapirin) in the first sample and a possibly Published on Web 01/26/2005

violative level of desfuroylceftiofur in the second, whereas the microbial assay identified the two samples as having only violative levels of a penicillin $\beta$-lactam.

Antibiotics are widely used at therapeutic levels, in humans as well as animals, for the treatment of bacterial infections. However, the use of subtherapeutic levels of antibiotics in foodproducing animals to increase bulk may lead to the emergence of antibiotic-resistant bacterial strains. In addition, antibiotic residues in milk or edible tissues are potential risks for individuals who are hypersensitive to antibiotics. In consequence, the dual use of antibiotics has become an increasingly important public health concern. Antibiotics approved for use in food-producing animals have established tolerances for detection of their residues in milk, kidney, muscle, and liver. Detection of these residues above the established tolerance level constitutes a violation. Numerous methods exist to detect and quantify antibiotic residues in milk and edible tissues; however, efforts to improve (or even replace) existing methods remain an active area of research.

Methods to detect and quantify antibiotics range from singleanalyte to multiresidue or multiclass methods. Single-analyte detection has the advantage that the method can be optimized for maximum recovery of a single analyte in a specific matrix. Single-analyte methods are highly favored by the pharmaceutical industry due to the regulatory approval process of any new drug. In contrast, multiresidue methods are designed to maximize the number of analytes detected within a particular class while recovery optimization remains an important but secondary issue. Multiclass methods are even more ambitious in their goal of maximizing the number of analytes detected among two of more drug classes. The more chemically dissimilar a group of analytes, the greater the difficulty of finding a single method that extracts and detects all the analytes in all matrixes with acceptable recoveries. Typically, multiresidue method development involves selecting compounds for analysis that are chemically similar. The more chemically similar a group of analytes, the more likely that a single method will be successful for detection of all analytes in

\footnotetext{
* To whom correspondence should be addressed. E-mail: cfagerquist@ pw.usda.gov.

$\dagger$ Western Regional Research Center.

* Eastern Regional Research Center.
} 
a particular matrix. Multiresidue (and multiclass) methods are favored by regulatory agencies as part of their mandate to monitor the food supply for a variety of regulated drugs and other chemical compounds.

One of the most widely used class of antibiotics are the $\beta$-lactams, which include penicillins and cephalosporins. Numerous methods have been developed for both single-analyte and multiresidue analysis of $\beta$-lactam antibiotics in milk and edible tissues. ${ }^{1-20}$ These methods range from single-analyte extraction and cleanup with liquid chromatography-ultraviolet detection (LC/UV) to multiresidue methods, which commonly use either liquid chromatography-mass spectrometry (LC/MS) or tandem mass spectrometry (LC/MS/MS). For example, Hornish et al. ${ }^{19}$ recently reported the multilaboratory trial of a single-analyte method to detect the total residues of ceftiofur by LC/UV. Ceftiofur is a cephalosporin $\beta$-lactam that upon intramuscular injection rapidly converts to the antimicrobial metabolite desfuroylceftiofur (DFC), which has a free thiol group. DFC binds reversibly to cysteine residues in peptides and proteins through disulfide bonds. The method devised by Hornish et al. involves reduction of all disulfide bonds in a sample thus releasing all bound DFC followed by acetylation of the DFC thiol group. ${ }^{19}$ Separation and detection of the acetylated DFC is then performed by LC/UV. Although such a method is excellent for measuring total residues of ceftiofur, it is not compatible with multiresidue analysis because the reduction and acetylation steps may result in chemical degradation of other $\beta$-lactam antibiotics present in a sample.

In a recent study, Fagerquist and Lightfield ${ }^{20}$ demonstrated confirmatory analysis of $11 \beta$-lactam antibiotics in bovine kidney tissue using solvent extraction followed by conventional solidphase extraction (SPE) cleanup with confirmation by LC/MS/

(1) Voyksner, R. D.; Tyczkowska, K. L.; Aronson, A. L. L. Chromatogr., B 1991, $567,389-404$.

(2) Moats, W. A. I. Chromatgr. 1992, 593, 15-20.

(3) Blanchflower, W. J.; Hewitt, S. A.; Kennedy, D. G. Analyst 1994, 119, 25952601.

(4) Moats, W. A. I. AOAC Int. 1994, 77, 41-45.

(5) Moats, W. A.; Harik-Khan R. I. AOAC Int. 1995, 78, 49-54.

(6) Moats, W. A.; Romanowski, R. D. L. Chromatogr., A 1998, 812, 237-247.

(7) Moats, W. A.; Romanowski, R. D. L. Agric. Food Chem. 1998, 46, 14101413.

(8) Moats, W. A.; Romanowski, R. D.; Medina, M. B. L. AOAC Int. 1998, 81, 1135-1140.

(9) Keever, J.; Voyksner, R. D.; Tyczkowska, K. L. I. Chromatogr., A 1998, $794,57-62$.

(10) Schermerhorn, P. G.; Chu, P. S.; Ngoh, M. A. I. AOAC Int. 1998, 81, 973977.

(11) Heller, D. N.; Ngoh, M. A. Rapid Commun. Mass Spectrom. 1998, 12, 20312040.

(12) Daeseleire, E.; De Ruyck H.; van Renterghem, R. Rapid Commun. Mass Spectrom. 2000, 14, 1404-1409.

(13) Riediker, S.; Stadler, R. H. Anal. Chem. 2001, 73, 1614-1621.

(14) Riediker, S.; Diserens, J. M.; Stadler, R. H. I. Agric. Food Chem. 2001, 49, 4171-4176.

(15) Bruno, F.; Curini, R.; Di Corcia, A.; Nazzari, M.; Samperi, R. L. Agric. Food Chem. 2001, 49, 3463-3470.

(16) Holstege, D. M.; Puschner, B.; Whitehead, G.; Galey, F. D. I. Agric. Food Chem. 2002, 50, 406-411.

(17) Ito, Y.; Ikai, Y.; Oka, H.; Matsumoto, H.; Miyazaki, Y.; Takeba, K.; Nagase, H. I. Chromatogr., A 2001, 911, 217-223.

(18) De Baere, S.; Cherlet, M.; Baert, K.; De Backer, P. Anal. Chem. 2002, 74, 1393-1401.

(19) Hornish, R. E.; Hamlow, P.; Brown, S. I. AOAC Int. 2003, 86: 30-38.

(20) Fagerquist, C. K.; Lightfield, A. R. Rapid Commun. Mass Spectrom. 2003, $17,660-671$.
MS analysis. In that study, LC/MS/MS was performed using a quadrupole ion trap mass spectrometer with an electrospray ionization (ESI) source. Although confirmatory analysis was achieved at tolerance levels for most of the analytes, quantitation was not successful due to a lack of linearity and reproducibility of calibration curves. The lack of linearity and reproducibility was possibly caused by the following: (1) ion source limitations; (2) suppression of analyte ionization by coeluting matrix contaminants; (3) competitive exclusion of analyte ions in the mass analyzer by more abundant matrix ions. Further experiments with this sample preparation method using a recently acquired triple quadrupole mass spectrometer produced dramatically improved results with respect to sensitivity, linearity, and reproducibility thus making quantitation possible.

In the current study, we report results obtained with instrumentation more appropriate to residue analysis in complex matrixes. In addition, we report a significant improvement in sample cleanup by replacing conventional SPE cleanup with dispersive solid-phase extraction (dispersive-SPE), a technique that greatly simplifies and accelerates sample cleanup. ${ }^{21}$ Confirmation and quantitation of fortified bovine kidney samples was performed using the new method at concentration levels of 5-1000 ng/g. We also report confirmation and quantitation results for 30 incurred bovine kidney samples that were previously analyzed using a semiquantitative microbial assay.

\section{EXPERIMENTAL SECTION}

Antibiotic Standards. Eleven $\beta$-lactam antibiotics were used in the present study: deacetylcephapirin (DECEPH), amoxicillin (AMOX), desfuroylceftiofur cysteine disulfide (DCCD), ampicillin (AMP), cefazolin (CFZN), penicillin G (PEN G), penicillin V (PEN V) used as an internal standard, oxacillin (OX), cloxacillin (CLOX), naficillin (NAF), and dicloxacillin (DICLOX). DECEPH was generously provided by the Food and Drug Adminstration (FDA) Center for Veterinary Medicine (Laurel, MD). AMOX, AMP, CFZN, PEN G, PEN V, CLOX, and NAF were obtained from U.S. Pharmacopeia (Rockville, MD). OX and DICLOX were obtained from Sigma (St. Louis, MO). DCCD was generously provided by Pharmacia, Animal Health Preclinical Development (Kalamazoo, MI). Individual stock solutions of each $\beta$-lactam were prepared at a concentration of $100 \mu \mathrm{g} / \mathrm{mL}$ in 50:50 methanol/water and stored in amber-colored bottles at $-20^{\circ} \mathrm{C}$. From the individual stock solutions, a mixed stock solution was prepared at a concentration of $10 \mu \mathrm{g} / \mathrm{mL}$ per analyte. Tenfold serial dilutions of the $10 \mu \mathrm{g} /$ $\mathrm{mL}$ mixed stock in methanol/water produced additional mixed stock solutions at concentrations of $1.0 \mu \mathrm{g} / \mathrm{mL}$ per analyte and $0.1 \mu \mathrm{g} / \mathrm{mL}$ per analyte. These mixed stock solutions were used to spike control tissue samples at concentrations ranging from 5 to $1000 \mathrm{ng} / \mathrm{g}$ and prepare matrix-matched standards (MMS) at concentrations ranging from 1 to $1000 \mathrm{ng} / \mathrm{g}$ for calibration curves. Individual and mixed stock solutions were replaced once a month. MMS and fortified samples (or incurred) were spiked with the same amount of internal standard (PEN V) on the day of the analysis at a concentration of either 500 or $250 \mathrm{ng} / \mathrm{g}$.

Sample Preparation: Overview. Incurred bovine kidney tissue samples were provided by the USDA Food Safety and Inspection Service (FSIS, St. Louis, MO) and stored in a $-80{ }^{\circ} \mathrm{C}$

(21) Anastassiades, M.; Lehotay, S. J.; Štajnbaher, D.; Schenck, F. J. I. AOAC Int. 2003, 86, 412-431. 
freezer upon arrival to our laboratory. Several 1.0-g portions of the kidney sample were analyzed. In order that the selected portions were representative of the whole sample, each sample was homogenized to a semisolid/semiliquid consistency using a RS1 2Y1 Robot Coupe food processor (Robot Coupe USA Inc., Ridgeland, MS). Fatty connective tissue was removed prior to homogenization. After homogenization, the sample was transferred to small plastic bags, labeled, and restored in the $-80^{\circ} \mathrm{C}$ freezer. Approximately 3-4 $\mathrm{h}$ after storage, the sample was prepared (in duplicate) by the method described below and analyzed by LC/ MS/MS to determine which, if any, analytes were present and to obtain an approximate estimate of their concentrations. No internal standard was added during this initial screening process. The following day, MMS were prepared at an appropriate concentration range using control kidney tissue. The incurred samples were prepared again in duplicate, as before, and MMS and incurred samples were analyzed by LC/MS/MS. PEN V was used as an internal standard in both incurred samples and MMS to correct for intersample instrument variability. The MMS were used to generate a calibration curve from which concentrations of incurred samples were calculated by interpolation. Separate experiments were conducted to determine the percent recovery of each analyte using this method by analyzing fortified control kidney samples. The percent recoveries were then used to calculate the actual concentrations of analytes in incurred tissue kidney samples.

Sample Preparation. Kidney tissue samples were prepared using a method similar to that described previously by Fagerquist and Lightfield. ${ }^{20}$ However, an important modification has been made to simplify and accelerate sample cleanup, which also improved overall analyte recovery, i.e., dispersive-SPE. ${ }^{21}$ Incurred tissue samples were prepared as follows. A 1.0-g portion of frozen, homogenized beef kidney tissue was deposited into a $50-\mathrm{mL}$ polypropylene centrifuge tube (Corning). Unused sample was restored at $-80{ }^{\circ} \mathrm{C}$. The sample was allowed to thaw to room temperature after which $2.0 \mathrm{~mL}$ of water and $8.0 \mathrm{~mL}$ of acetonitrile $(\mathrm{MeCN})$ were added. The capped tube was vortexed briefly and then placed on a free-standing vortex mixer for $5.0 \mathrm{~min}$. The sample tube was then centrifuged at $4500 \mathrm{rpm}(2790 \mathrm{~g}), 4^{\circ} \mathrm{C}$ for 5.0 min using a fixed-angle rotorhead A500 on a Sorvall RT 6000 $B$ refrigerated centrifuge (Dupont). After centrifugation, a solid pellet of protein material formed at the bottom of the tube. The ratio of $1 \mathrm{~g}$ of tissue to $2 \mathrm{~mL}$ of water and $8 \mathrm{~mL}$ of $\mathrm{MeCN}$ was found to be optimal for antibiotic extraction/sample deproteinization. ${ }^{7,20}$ Approximately $10 \mathrm{~mL}$ of supernatant was decanted into a 15-mL polypropylene tube (Corning), which contained $0.5 \mathrm{~g}$ of Bakerbond $\mathrm{C}_{18}$ sorbent, $40-\mu \mathrm{m}$ particle size (J. T. Baker, Phillipsburg, NJ). The tube was then capped and inverted several times by hand until the sorbent material dispersed thoroughly with the extract. This constitutes the dispersive-SPE cleanup step. The simplicity of this technique contrasts favorably with the more laborious conventional SPE cleanup that requires column conditioning, gravitational loading, and elution of sample, as well as the need for a SPE cartridge manifold. ${ }^{20}$ After the dispersive-SPE step, the tube was then centrifuged at $4500 \mathrm{rpm}(2750 \mathrm{~g})$ at $4{ }^{\circ} \mathrm{C}$ for 5.0 min using a fixed-angle rotorhead A384, which resulted in the sorbent material being deposited at the bottom of the tube. Approximately $10 \mathrm{~mL}$ of supernatant was transferred using a disposable pipet to a $20 \times 150 \mathrm{~mm}$ disposable glass cultured tube

\section{Table 1. HPLC Chromatographic Conditions ${ }^{a}$}

\begin{tabular}{|c|c|c|c|}
\hline \multirow{2}{*}{$\begin{array}{l}\text { time } \\
(\min )\end{array}$} & \multirow{2}{*}{$\begin{array}{l}\text { flow rate } \\
\text { (mL/min) }\end{array}$} & \multicolumn{2}{|c|}{ mobile phase } \\
\hline & & $\overline{\mathrm{A}(\%)}$ & B (\%) \\
\hline 0.0 & 0.30 & 100 & 0.0 \\
\hline 22.0 & 0.30 & 0.0 & 100 \\
\hline 22.1 & 0.50 & 0.0 & 100 \\
\hline 27.0 & 0.50 & 0.0 & 100 \\
\hline 28.0 & 0.50 & 100 & 0.0 \\
\hline 31.0 & 0.50 & 100 & 0.0 \\
\hline 31.1 & 0.30 & 100 & 0.0 \\
\hline 33.0 & 0.30 & 100 & 0.0 \\
\hline
\end{tabular}

${ }^{a}$ Mobile phase A, $0.1 \%$ formic acid; mobile phase B, $50 \%$ methanol, $50 \%$ acetonitrile, $0.1 \%$ formic. Divert valve: $0.0-8.0 \mathrm{~min}$ (waste), $8.0-$ $24.0 \mathrm{~min}$ (MS), 24.0-33.0 $\mathrm{min}$ (waste).

\section{Table 2. Mass Spectrometry Instrument Parameters Common to All Analytes}

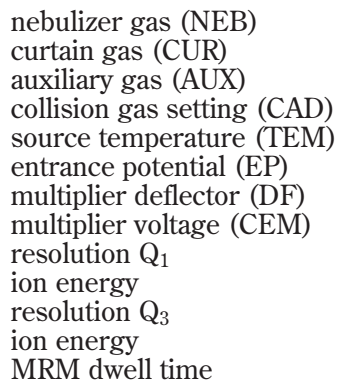

\author{
$12.0(\mathrm{au})$ \\ 10.0 (au) \\ $6000 \mathrm{~mL} / \mathrm{min}$ \\ 12.0 (au) \\ $550{ }^{\circ} \mathrm{C}$ \\ $10.0 \mathrm{~V}$ \\ $-400 \mathrm{~V}$ \\ 2200 or $2400 \mathrm{~V}$ \\ unit \\ 0.60 or $0.70 \mathrm{~V}$ \\ Unit \\ 0.70 or $-0.50 \mathrm{~V}$ \\ $50 \mathrm{~ms}$
}

(VWR Scientific Products) with minimal carryover of sorbent. The tube was then placed in a TurboVap LV evaporator (Zymark, Hopkinton, MA) set at $38-40{ }^{\circ} \mathrm{C}$ with maximum nitrogen flow. Extraction solvents were evaporated to a final aqueous volume of 1.0-1.3 $\mathrm{mL}$, which took $30-40 \mathrm{~min}$. The extract was then transferred by disposable pipet to a Luer-lock 5.0-mL glass syringe (Micro-Mate, Popper \& Sons, Inc., New York, NY) fitted with a $0.2-\mu \mathrm{m}$ polyethersulfone syringe filter (Whatman, Puradisc, $25 \mathrm{AS}$, Clifton, NJ). The sample was syringe filtered directly into a glass HPLC autosampler vial. A fixed amount of internal standard (PEN V) was added to the vial. If necessary, water was added to bring the final volume to $1.5 \mathrm{~mL}$.

Analyte recoveries were determined from fortification experiments replicated over three separate days. Kidney tissue was obtained from a local supermarket, homogenized, extracted, cleaned up, analyzed by LC/MS/MS, and found to be free of the 11 antibiotics used in this study and thus suitable for use as control tissue for fortified experiments. Homogenized control tissue was allowed to thaw to room temperature prior to fortification of $1.0-\mathrm{g}$ portions. Fortification concentrations were 5, 10, 25, 50, 100, 250, 500 , and $1000 \mathrm{ng} / \mathrm{g}$. After fortification, the samples were vortexed/ mixed for $10-15 \mathrm{~s}$ followed by a pause of $5.0 \mathrm{~min}$ before addition of the extraction/deproteinization solvents $(8 \mathrm{~mL}$ of $\mathrm{MeCN}+2$ $\mathrm{mL}$ of water). The reason for this "pause" was to reproduce, as closely as possible, the conditions under which analytes in incurred samples were exposed to homogenized tissue. Upon addition of the extraction solvents, the fortified samples were processed identically to the incurred samples.

MMS were prepared and analyzed concurrently with fortified and incurred samples in order to accurately measure their concentrations. MMS correct for matrix suppression (or enhance- 
Table 3. Ion Source and Analyzer Parameters: Collision Energy (CE), Collision Exit Potential (CXP), Ion Source Voltage (IS), Declustering Potential (DP), and Focusing Potential (FP)

\begin{tabular}{|c|c|c|c|c|c|c|c|}
\hline analyte & $\begin{array}{l}\operatorname{transition} \\
(m / z)\end{array}$ & $\begin{array}{l}\text { CE } \\
\text { (V) }\end{array}$ & $\begin{array}{c}\text { CXP } \\
\text { (V) }\end{array}$ & $\begin{array}{l}\text { IS } \\
\text { (V) }\end{array}$ & $\begin{array}{l}\text { DP } \\
\text { (V) }\end{array}$ & $\begin{array}{l}\text { FP } \\
\text { (V) }\end{array}$ & $\begin{array}{c}\text { period } \\
(\mathrm{min})\end{array}$ \\
\hline \multirow[t]{4}{*}{ DECEPH } & $382.0 \rightarrow 112.0$ & 35.0 & 10.0 & 5000 & 36.0 & 130 & $0.0-11.2$ \\
\hline & $382.0 \rightarrow 152.0$ & 37.0 & 14.0 & 5000 & 36.0 & 130 & $0.0-11.2$ \\
\hline & $382.0 \rightarrow 226.0$ & 27.0 & 10.0 & 5000 & 36.0 & 130 & $0.0-11.2$ \\
\hline & $382.0 \rightarrow 292.0$ & 21.0 & 22.0 & 5000 & 36.0 & 130 & $0.0-11.2$ \\
\hline \multirow[t]{3}{*}{ AMOX } & $366.0 \rightarrow 349.0$ & 13.0 & 10.0 & 5000 & 21.0 & 90 & $0.0-11.2$ \\
\hline & $366.0 \rightarrow 114.0$ & 27.0 & 8.0 & 5000 & 21.0 & 90 & $0.0-11.2$ \\
\hline & $366.0 \rightarrow 208.0$ & 19.0 & 14.0 & 5000 & 21.0 & 90 & $0.0-11.2$ \\
\hline \multirow[t]{3}{*}{$\mathrm{DCCD}$} & $549.0 \rightarrow 241.0$ & 29.0 & 16.0 & 5500 & 41.0 & 160 & $11.2-12.7$ \\
\hline & $549.0 \rightarrow 366.0$ & 31.0 & 10.0 & 5500 & 41.0 & 160 & $11.2-12.7$ \\
\hline & $549.0 \rightarrow 397.0$ & 27.0 & 12.0 & 5500 & 41.0 & 160 & $11.2-12.7$ \\
\hline \multirow[t]{4}{*}{ AMP } & $350.0 \rightarrow 192.0$ & 19.0 & 18.0 & 5000 & 26.0 & 110 & $12.7-14.2$ \\
\hline & $350.0 \rightarrow 106.0$ & 23.0 & 6.0 & 5000 & 26.0 & 110 & $12.7-14.2$ \\
\hline & $350.0 \rightarrow 160.0$ & 23.0 & 28.0 & 5000 & 26.0 & 110 & $12.7-14.2$ \\
\hline & $350.0 \rightarrow 174.0$ & 23.0 & 10.0 & 5000 & 26.0 & 110 & $12.7-14.2$ \\
\hline \multirow[t]{2}{*}{ CFZN } & $455.0 \rightarrow 323.0$ & 17.0 & 10.0 & 5000 & 31.0 & 130 & $14.2-19.7$ \\
\hline & $455.0 \rightarrow 156.0$ & 23.0 & 13.0 & 5000 & 31.0 & 130 & $14.2-19.7$ \\
\hline \multirow[t]{2}{*}{ PEN G } & $335.0 \rightarrow 160.0$ & 17.0 & 10.0 & 5000 & 36.0 & 140 & $19.7-20.95$ \\
\hline & $335.0 \rightarrow 176.0$ & 19.0 & 12.0 & 5000 & 36.0 & 140 & $19.7-20.95$ \\
\hline \multirow[t]{2}{*}{ PEN V (IS) } & $351.0 \rightarrow 160.0$ & 17.0 & 10.0 & 5000 & 31.0 & 130 & $20.95-21.85$ \\
\hline & $351.0 \rightarrow 192.0$ & 15.0 & 8.0 & 5000 & 31.0 & 130 & $20.95-21.85$ \\
\hline \multirow[t]{2}{*}{ OXA } & $402.0 \rightarrow 160.0$ & 19.0 & 10.0 & 5000 & 31.0 & 140 & $20.95-21.85$ \\
\hline & $402.0 \rightarrow 243.0$ & 19.0 & 18.0 & 5000 & 31.0 & 140 & $20.95-21.85$ \\
\hline \multirow[t]{3}{*}{ CLOX } & $436.0 \rightarrow 160.0$ & 21.0 & 10.0 & 5000 & 31.0 & 130 & $21.85-24.0$ \\
\hline & $436.0 \rightarrow 277.0$ & 19.0 & 20.0 & 5000 & 31.0 & 130 & $21.85-24.0$ \\
\hline & $438.0 \rightarrow 279.0$ & 19.0 & 20.0 & 5000 & 31.0 & 130 & $21.85-24.0$ \\
\hline \multirow[t]{2}{*}{ NAF } & $415.0 \rightarrow 199.0$ & 19.0 & 14.0 & 5000 & 26.0 & 100 & $21.85-24.0$ \\
\hline & $415.0 \rightarrow 256.0$ & 23.0 & 18.0 & 5000 & 26.0 & 100 & $21.85-24.0$ \\
\hline \multirow[t]{3}{*}{ DICLOX } & $470.0 \rightarrow 160.0$ & 21.0 & 10.0 & 5000 & 36.0 & 160 & $21.85-24.0$ \\
\hline & $470.0 \rightarrow 311.0$ & 21.0 & 22.0 & 5000 & 36.0 & 160 & $21.85-24.0$ \\
\hline & $472.0 \rightarrow 313.0$ & 21.0 & 22.0 & 5000 & 36.0 & 160 & $21.85-24.0$ \\
\hline
\end{tabular}

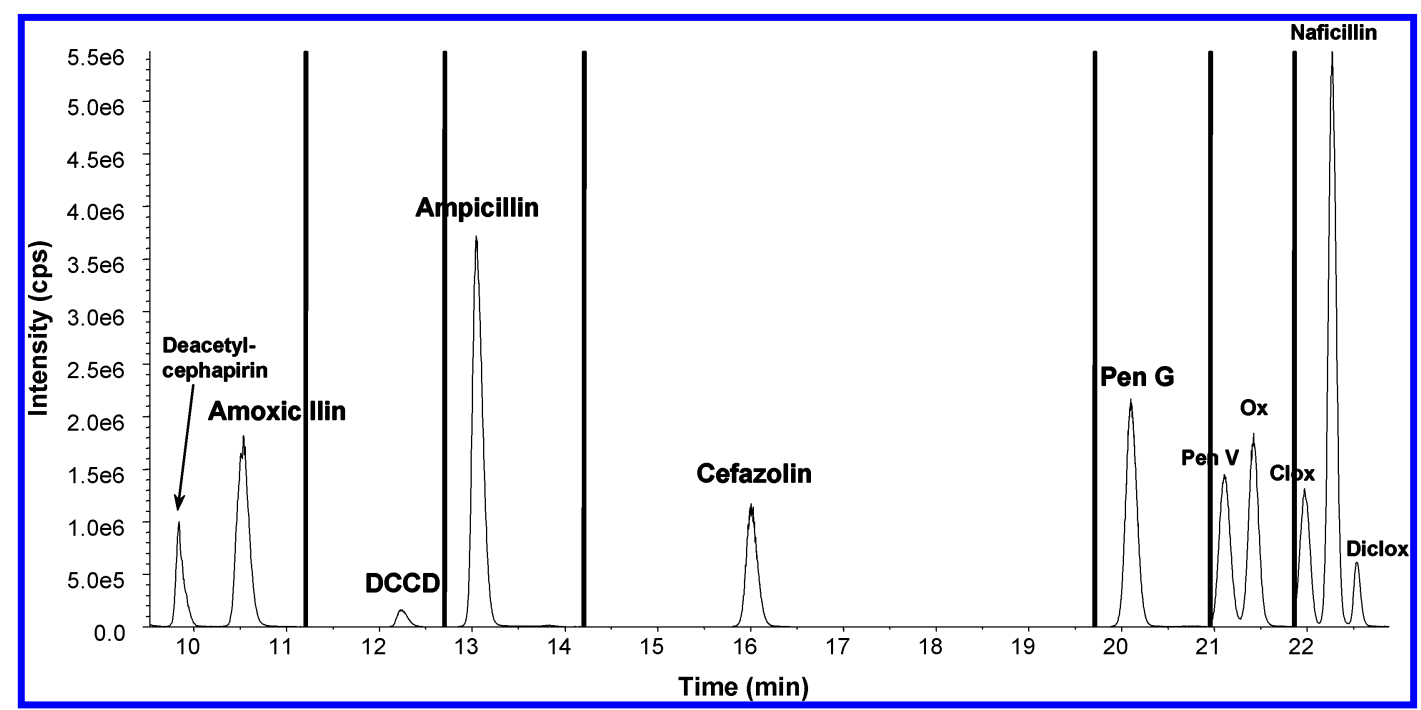

Figure 1. Total ion $\mathrm{LC} / \mathrm{MS} / \mathrm{MS}$ of a MMS at a concentration of $250 \mathrm{ng} / \mathrm{g}$. Vertical bars delineate preset acquisition windows.

ment) effects during analyte ionization. MM extract was generated from 1.0-g portions of control tissue that was processed identically to that of incurred tissue. Antibiotic standards were added directly to the autosampler vials at concentrations of $0,1,5,10,25,50$, $100,250,500$, and $1000 \mathrm{ng} / \mathrm{g}$ (or higher if incurred sample concentrations required it). If necessary, water was added to adjust the final volume of the MMS to $1.5 \mathrm{~mL}$.

Liquid Chromatography/Tandem Mass Spectrometry. Samples were analyzed by LC/MS/MS using a high-performance liquid chromatograph (1100 LC binary pump, Agilent) interfaced to a triple quadrupole mass spectrometer (API 3000, Applied Biosystems/MDS Sciex, Toronto, ON, Canada). Sample injection volume was $100 \mu \mathrm{L}$ using an Agilent 1100 autosampler. Chromatographic separation was performed with a YMC ODS-AQ column (Waters, $4.6 \times 50 \mathrm{~mm}$, particle size $3 \mu \mathrm{m}$; pore size 120 $\AA$ ). LC was used to chromatographically separate matrix contaminants and analytes. No column heater was used. Early-eluting matrix contaminants were diverted to waste using a Valco divert valve. The timing of LC gradients and valve positions are given in Table 1. An LC flow rate of $0.300 \mathrm{~mL} / \mathrm{min}$ was found to be 
Table 4. Relative MRM TIC (\%) of Each Analyte (As Measured in MMS) of the Third Recovery Study Compared to the MRM TIC of Each Analyte in the Second Recovery Study (Also Measured in MMS)a

$\begin{array}{lrrrcr}\text { analyte } & 1 \mathrm{ng} / \mathrm{g} & 10 \mathrm{ng} / \mathrm{g} & 100 \mathrm{ng} / \mathrm{g} & 1000 \mathrm{ng} / \mathrm{g} & \text { av } \pm \mathrm{SD} \\ \text { DECEPH } & & 95 \pm 10 & 93 \pm 5 & 89 \pm 11 & 92 \pm 5 \\ \text { AMOX } & 91 \pm 7 & 93 \pm 1 & 101 \pm 2 & 110 \pm 3 & 99 \pm 2 \\ \text { DCCD } & 80 \pm 4 & 103 \pm 2 & 104 \pm 2 & 117 \pm 2 & 101 \pm 1 \\ \text { AMP } & 100 \pm 1 & 98 \pm 0 & 103 \pm 1 & 105 \pm 1 & 101 \pm 1 \\ \text { CFZN } & 92 \pm 1 & 97 \pm 1 & 96 \pm 0 & 95 \pm 1 & 95 \pm 1 \\ \text { PEN G } & 93 \pm 1 & 99 \pm 2 & 109 \pm 0 & 104 \pm 1 & 101 \pm 1 \\ \text { PEN V } & & & & 93 \pm 6 & \\ & & & & (250 \mathrm{ng} / \mathrm{g}) & \\ \text { OXA } & 88 \pm 3 & 90 \pm 3 & 103 \pm 4 & 100 \pm 2 & 95 \pm 2 \\ \text { CLOX } & 71 \pm 5 & 79 \pm 1 & 88 \pm 4 & 92 \pm 2 & 82 \pm 2 \\ \text { NAF } & 95 \pm 4 & 93 \pm 1 & 101 \pm 0 & 100 \pm 1 & 97 \pm 1 \\ \text { DICLOX } & 93 \pm 15 & 81 \pm 5 & 88 \pm 2 & 94 \pm 1 & 89 \pm 4\end{array}$

${ }^{a}$ The same stock solutions were used in preparing MMS and fortified samples for the second and third recovery studies. Twelve days elapsed between the second and third recovery studies. During that interval, stock solutions were stored in $-20^{\circ} \mathrm{C}$ freezer in 50:50 methanol/water. Instrument parameters were identical for both studies.

optimal for baseline separation of analytes as well as efficient ESI. Samples were ionized in positive ESI mode using Turboionspray (MDS Sciex).

Table 2 summarizes mass spectrometry parameters that were common to the analysis of all $11 \beta$-lactam antibiotics. MS/MS analysis was performed in MRM mode, which monitored two to four of the most abundant precursor $\rightarrow$ fragment ion transitions of each analyte. An extracted ion chromatogram (XIC) was generated for each precursor $\rightarrow$ fragment ion transition. The XIC peak was integrated, and its area was summed to the areas of the other XIC transitions of a particular analyte. This total integrated area was used for quantitation of each particular analyte. The ratio of the XIC integrated areas of the two most abundant and structurally significant transitions of an analyte were used for confirmation. Given the total number of transitions, i.e., 30, and the necessity to obtain a sufficient number of data points across a chromatographic peak, it was not possible (or necessary) to monitor all the transitions of all the analytes for the entire chromatographic cycle. Instead, MRM experiments were grouped to monitor the transitions of particular analytes during a prespecified elution window. Table 3 summarizes the analyte transitions and their associated instrument parameters.

Data Analysis: Confirmation and Quantitation. Calibration curves of MMS were fitted to a first- or second-order polynomial using a graphing/mathematical analysis software program Origin, version 7.0 (OriginLab, Northampton, MA). Consistent with analyte ionization by ESI, a $1 / x$ weighting was used. The concentrations of incurred and fortified samples were interpolated (or occasionally extrapolated) from the MMS calibration curves.

\section{RESULTS AND DISCUSSION}

Figure 1 shows a typical total ion current (TIC) chromatogram of a $250 \mathrm{ng} / \mathrm{g}$ MMS. The TIC chromatogram is a summation of the ion signal generated by all the precursor $\rightarrow$ fragment ion transitions in a designated acquisition window. Seven separate data acquisition windows were used, and each is delineated by vertical bars. The precursor $\rightarrow$ fragment ion transitions monitored for an

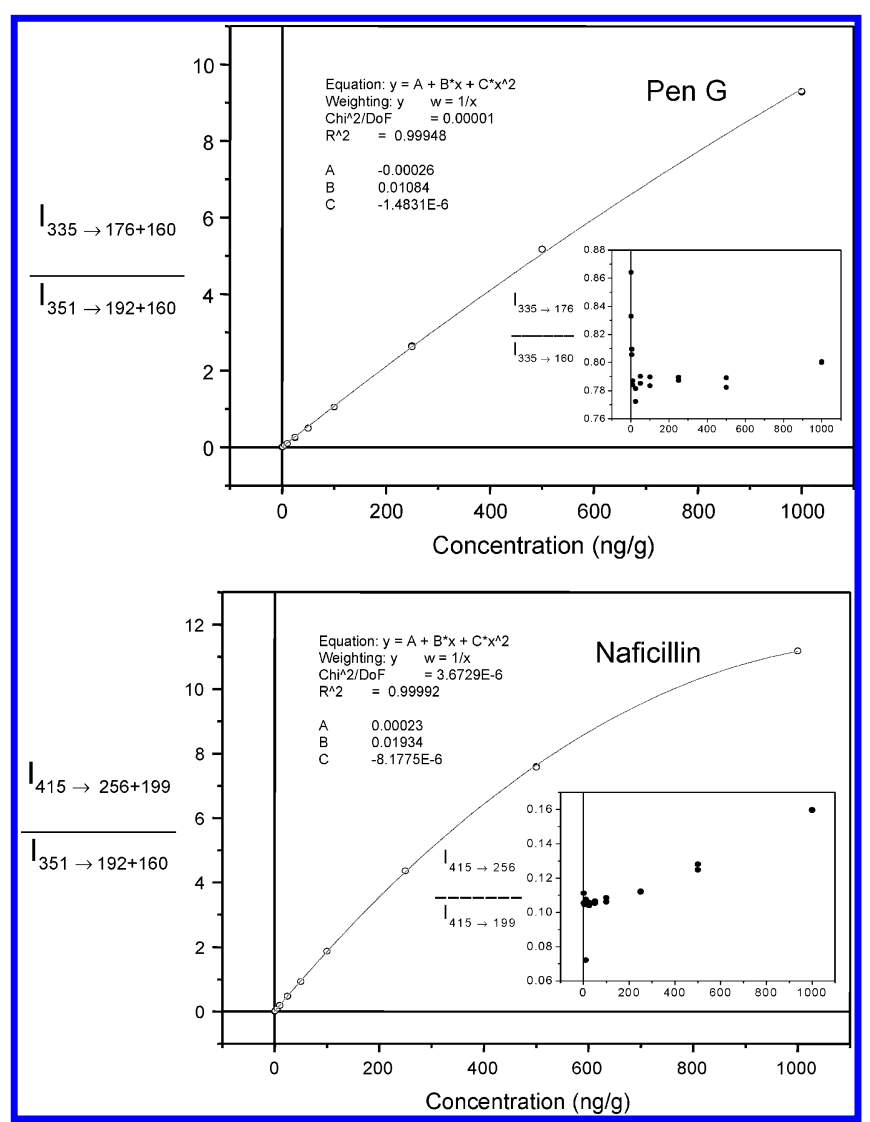

Figure 2. Top panel: MMS calibration curve for PEN G normalized with respect to the internal standard (PEN V). Inset shows the confirmatory ion ratio of the intensities of the two precursor $\rightarrow$ fragment ion transitions as a function of concentration. Bottom panel: MMS calibration curve for NAF normalized with respect to the internal standard (PEN V). Inset shows the confirmatory ion ratio of the intensities of the two precursor $\rightarrow$ fragment ion transitions as a function of concentration.

analyte constituted a separate experiment within a particular window. If an acquisition window contained multiple experiments (i.e., analytes), the experiments were continuously concatenated for the duration of that window. During the course of these experiments ( $\sim 2$ months), we would observe slight shifts in analyte elution time, which required adjustment of an acquisition window.

Compound Stability of $\boldsymbol{\beta}$-Lactams in Methanol/Water. Tyczkowska et al. previously reported degradation of CLOX in $100 \mathrm{ppm}$ stock solutions stored at $-20^{\circ} \mathrm{C}$ over a period of 8 weeks using a variety of solvents. ${ }^{22}$ In that study, they reported complete degradation of CLOX in 50:50 methanol/water in two weeks. Table 4 shows the relative MRM TIC (\%) of each analyte in the third recovery study (as measured in MMS) compared to the MRM TIC of each analyte in the second recovery study (also measured in MMS). The same stock solutions were used in the second and third recovery studies, which were prepared 2 days prior to their use in the second recovery study. An interval of 12 days elapsed between the second and third recovery studies, and during that interval, stock solutions were stored in $-20^{\circ} \mathrm{C}$ freezer in 50:50 methanol/water. Instrument parameters for the second and third

(22) Tyczkowska, K. L.; Voyksner, R. D.; Aronson, A. L. L. Chromatogr. 1992, 594, 195-201. 
Table 5. Correlation Coefficients $\left(R^{2}\right)$ of Calibration Curves of Matrix-Matched Standards Used in Recovery Studies (Rec) and Analysis of 30 Incurred Samples (Inc) ${ }^{a}$

\begin{tabular}{|c|c|c|c|c|c|c|c|c|}
\hline analyte & first Rec & $\begin{array}{l}\text { Inc } 11-13 \\
\text { and } 17-18\end{array}$ & $\begin{array}{l}\text { Inc } 14-16 \\
\text { and } 19-20\end{array}$ & $\begin{array}{l}\text { Inc } 1-6 \\
\text { and } 8-10\end{array}$ & Inc $21-30$ & Inc 7 & $\begin{array}{l}\text { second } \\
\text { Rec }\end{array}$ & $\begin{array}{l}\text { third } \\
\text { Rec }\end{array}$ \\
\hline DECEPH & 0.96765 & & 0.99263 & 0.99300 & 0.99942 & & 0.99225 & 0.99076 \\
\hline AMOX & 0.99276 & & & & & & 0.99847 & 0.99737 \\
\hline $\mathrm{DCCD}$ & 0.99937 & 0.99831 & & 0.99801 & 0.99657 & 0.99892 & 0.99765 & 0.99928 \\
\hline AMP & 0.99943 & & 0.99982 & 0.99982 & & & 0.99916 & 0.99966 \\
\hline $\mathrm{CFZN}$ & 0.99945 & & & & & & 0.99948 & 0.99952 \\
\hline PEN G & 0.99972 & 0.99951 & 0.99955 & 0.99987 & 0.99942 & & 0.99948 & 0.99971 \\
\hline OXA & 0.99972 & & & & & & 0.99975 & 0.99985 \\
\hline CLOX & 0.99970 & & & & & & 0.99957 & 0.99967 \\
\hline NAF & 0.99917 & & & & & & 0.99992 & 0.99965 \\
\hline DICLOX & 0.99925 & & & & & & 0.99959 & 0.99981 \\
\hline
\end{tabular}

${ }^{a}$ Best fit was obtained using a $1 / x$ weighted second-order polynomial for most calibration curves. Analyses performed on separate days in chronological order left-to-right over a period of $\sim 2$ months.

recovery studies were identical. As shown in Table 4, we did not observe any significant decline in analyte ion signal in the MMS for the third recovery study compared to the MMS for the second recovery study, except perhaps for a $20 \%$ decline for CLOX and $10 \%$ decline for DICLOX. Confirmation data for analyte identification for the second and third recovery studies are shown in the middle and bottom panel of Table 6, respectively.

Calibration Curves of Matrix-Matched Standards. Figure 2 (top panel) shows a typical MMS calibration curve of PEN G. The best fit of the MMS was obtained with a second-order polynomial function generated using a nonlinear curve-fitting function of the graphing software. As shown, the summation of the integrated areas of the two transitions of PEN G, i.e., $I_{335 \rightarrow 160}$ $+I_{335 \rightarrow 176}$, were normalized with respect to the summation of integrated areas of the two transitions of the internal standard PEN V $\left(I_{351 \rightarrow 160}+I_{351 \rightarrow 192}\right)$. The data were also given a $1 / x$ weighting. An inset in Figure 2 (top panel) shows the ratio of the two transitions of PEN G as a function of concentration. $I_{335 \rightarrow 176} /$ $I_{335 \rightarrow 160}$ remains relatively constant as a function of concentration except at very low concentrations. Figure 2 (bottom panel) shows a typical MMS calibration curve for NAF which shows the most pronounced nonlinearity observed in MMS calibration curves for any of the analytes in this study. Two transitions were monitored for NAF: $m / z 415 \rightarrow 256$ and $m / z 415 \rightarrow 199$. The inset of Figure 2 (bottom panel) shows the confirmation ratio $I_{415 \rightarrow 256} / I_{415 \rightarrow 199}$ as a function of concentration. The ratio of the two transitions $\left(I_{415 \rightarrow 256} / I_{415 \rightarrow 199}\right)$ shows an increase, albeit within a narrow range, in the confirmation ratio as a function of concentration. The origin of this change is likely due to detector nonlinearity. The API 3000 uses a horn-shaped channel electron multiplier (CEM) for ion detection. Ions exiting the third quadrupole are deflected directly into the horn of the detector striking its surface and initiating a cascade of electrons. CEM detectors have an S-shaped response curve. In consequence, the number of ions that strike the detector corresponds linearly to the amount of current generated from the detector within a limited range. At the high end of the response curve, the current generated from the detector under-represents the actual number of ions striking the detector because of saturation of its elements during the electron cascade. It is possible that the increase in $I_{415 \rightarrow 256} / I_{415 \rightarrow 199}$ as a function of concentration is due to detector saturation by $I_{415 \rightarrow 199}$ whereas $I_{415 \rightarrow 256}$, whose signal intensity is eight times less intense than $I_{415 \rightarrow 199}$, does not saturate the detector or saturates it to a lesser extent. In other words, $I_{415 \rightarrow 256}$ and $I_{415 \rightarrow 199}$ are on different regions of the detector response curve, and thus, the confirmation ratio increases as a function of concentration. As shown in Figure 1, the ionization efficiency of NAF is relatively high among the antibiotics in the present study, and this high ionization efficiency would also contribute to detector saturation by its most abundant transition, i.e., $m / z 415 \rightarrow 199$. AMP also possesses a high ionization efficiency, and one might expect to observe a similar detector saturation. This was indeed found to be the case.

It is possible, of course, to eliminate detector saturation by simply reducing the detector gain by lowering the voltage across the detector. However, developing multiresidue methods that use mass spectrometric detection often requires adjusting instrument parameters to compromise settings that are adequate for the monitoring of all analytes but not necessarily optimal for each analyte at every concentration. Lowering the detector gain to avoid saturation of the most abundant transition of an analyte that has the highest ionization efficiency may result in a loss of detection sensitivity for the least abundant transition of an analyte that has the lowest ionization efficiency. The MMS used in the present study covered a 3 orders-of-magnitude concentration range. Normally, it is only necessary for standards to cover a concentration range of $1 /{ }_{2} X, X$, and $2 X$ (where $X$ is the tolerance or maximum residue limit of the analyte). However, in the present multiresidue study, the established tolerances of the analytes ranged as follows: $10,50,100$, and $8000 \mathrm{ng} / \mathrm{g}$. In addition, several of the analytes in the present study do not have established tolerances, and thus detection of these analytes at any concentration is violative. Thus, a wide MMS concentration range was necessary. Finally, nonlinear calibration curves do not invalidate their use in the calculation of concentrations of known (fortified) or unknown (incurred) samples as long as the interpolation of nonlinear curves is sufficiently accurate. The correlation coefficients $\left(R^{2}\right)$ of the calibration curves used in recovery studies and analysis of incurred samples are summarized in Table 5 . Best fit was obtained using a $1 / x$ weighted second-order polynomial for most calibration curves.

Confirmation and Quantitation of Fortified Samples. Table 6 summarizes the confirmatory analysis of fortified samples in three recovery studies. Stock solutions used in preparing fortified and MMS samples were 7 days old at the time of the first recovery 
Table 6. Confirmatory Analysis of Fortified Samples in Three Recovery Studies ${ }^{a}$

\begin{tabular}{|c|c|c|c|c|c|c|c|}
\hline \multirow[b]{2}{*}{ analyte } & \multirow{2}{*}{$\begin{array}{c}\text { tolerance } \\
\text { level (ng/g) }\end{array}$} & \multirow{2}{*}{$\begin{array}{c}\text { fortified } \\
\text { concn (ng/g) }\end{array}$} & \multirow{2}{*}{$\underset{\text { ions }}{\text { fragment }}$} & \multicolumn{2}{|c|}{ fortified } & \multicolumn{2}{|c|}{ matrix-matched std } \\
\hline & & & & ion ratio & $t_{\mathrm{R}}(\min )$ & ion ratio & $t_{\mathrm{R}}(\min )$ \\
\hline \multicolumn{8}{|c|}{ First Recovery Study } \\
\hline DECEPH & $100^{b}$ & 100 & $292 / 152$ & $0.859 \pm 0.024$ & 9.84 & $0.851 \pm 0.049$ & 9.86 \\
\hline AMOX & 10 & 10 & $114 / 349$ & $0.446 \pm 0.049$ & 10.49 & $0.423 \pm 0.003$ & 10.51 \\
\hline $\mathrm{DCCD}$ & $8000^{c}$ & 1000 & $397 / 241$ & $0.492 \pm 0.003$ & 12.20 & $0.495 \pm 0.002$ & 12.20 \\
\hline AMP & 10 & 10 & $192 / 106$ & $0.266 \pm 0.004$ & 13.01 & $0.271 \pm 0.002$ & 13.02 \\
\hline CFZN & $d$ & 10 & $156 / 323$ & $0.364 \pm 0.003$ & 15.96 & $0.360 \pm 0.008$ & 15.98 \\
\hline PEN G & 50 & 50 & $176 / 160$ & $0.804 \pm 0.006$ & 20.09 & $0.803 \pm 0.001$ & 20.11 \\
\hline PEN V & $d$ & 500 & $192 / 160$ & $0.065 \pm 0.001$ & 21.09 & $0.065 \pm 0.001$ & 21.09 \\
\hline OXA & $d$ & 10 & $243 / 160$ & $0.744 \pm 0.001$ & 21.40 & $0.751 \pm 0.013$ & 21.41 \\
\hline CLOX & 10 & 10 & $277 / 160$ & $0.949 \pm 0.009$ & 21.94 & $0.919 \pm 0.010$ & 21.96 \\
\hline NAF & $d$ & 10 & $256 / 199$ & $0.121 \pm 0.003$ & 22.26 & $0.120 \pm 0.003$ & 22.27 \\
\hline DICLOX & $d$ & 10 & $311 / 160$ & $0.522 \pm 0.051$ & 22.52 & $0.497 \pm 0.007$ & 22.53 \\
\hline \multicolumn{8}{|c|}{ Second Recovery Study } \\
\hline DECEPH & $100^{b}$ & 100 & $292 / 152$ & $0.793 \pm 0.006$ & 10.75 & $0.804 \pm 0.017$ & 10.76 \\
\hline AMOX & 10 & 10 & $114 / 349$ & $0.388 \pm 0.001$ & 11.32 & $0.405 \pm 0.005$ & 11.32 \\
\hline DCCD & $8000^{c}$ & 1000 & $397 / 241$ & $0.482 \pm 0.016$ & 13.07 & $0.484 \pm 0.002$ & 13.02 \\
\hline AMP & 10 & 10 & $192 / 106$ & $0.326 \pm 0.007$ & 13.82 & $0.326 \pm 0.002$ & 13.83 \\
\hline $\mathrm{CFZN}$ & $d$ & 10 & $156 / 323$ & $0.332 \pm 0.009$ & 16.62 & $0.341 \pm 0.001$ & 16.61 \\
\hline PEN G & 50 & 50 & $176 / 160$ & $0.784 \pm 0.001$ & 20.59 & $0.788 \pm 0.004$ & 20.61 \\
\hline PEN V & $d$ & 250 & $192 / 160$ & $0.065 \pm 0.001$ & 21.57 & $0.065 \pm 0.001$ & 21.58 \\
\hline OXA & $d$ & 10 & $243 / 160$ & $0.907 \pm 0.013$ & 21.81 & $0.894 \pm 0.015$ & 21.80 \\
\hline CLOX & 10 & 10 & $277 / 160$ & $1.095 \pm 0.068$ & 22.24 & $1.080 \pm 0.018$ & 22.25 \\
\hline NAF & $d$ & 10 & $256 / 199$ & $0.106 \pm 0.001$ & 22.48 & $0.106 \pm 0.002$ & 22.48 \\
\hline DICLOX & $d$ & 10 & $311 / 160$ & $0.632 \pm 0.074$ & 22.71 & $0.668 \pm 0.044$ & 22.70 \\
\hline \multicolumn{8}{|c|}{ Third Recovery Study } \\
\hline DECEPH & $100^{b}$ & 100 & $292 / 152$ & $0.865 \pm 0.005$ & 10.85 & $0.881 \pm 0.009$ & 10.90 \\
\hline AMOX & 10 & 10 & $114 / 349$ & $0.374 \pm 0.008$ & 11.48 & $0.411 \pm 0.009$ & 11.49 \\
\hline DCCD & $8000^{c}$ & 1000 & $397 / 241$ & $0.470 \pm 0.001$ & 13.12 & $0.472 \pm 0.002$ & 13.09 \\
\hline AMP & 10 & 10 & $192 / 106$ & $0.309 \pm 0.003$ & 13.96 & $0.314 \pm 0.005$ & 13.98 \\
\hline $\mathrm{CFZN}$ & $d$ & 10 & $156 / 323$ & $0.336 \pm 0.015$ & 16.77 & $0.325 \pm 0.004$ & 16.79 \\
\hline PEN G & 50 & 50 & $176 / 160$ & $0.804 \pm 0.001$ & 20.70 & $0.806 \pm 0.003$ & 20.71 \\
\hline PEN V & $d$ & 250 & $192 / 160$ & $0.068 \pm 0.000$ & 21.66 & $0.067 \pm 0.000$ & 21.64 \\
\hline OXA & $d$ & 10 & $243 / 160$ & $0.913 \pm 0.015$ & 21.92 & $0.911 \pm 0.008$ & 21.92 \\
\hline CLOX & 10 & 10 & $277 / 160$ & $1.059 \pm 0.092$ & 22.31 & $1.056 \pm 0.004$ & 22.30 \\
\hline NAF & $d$ & 10 & $256 / 199$ & $0.106 \pm 0.001$ & 22.54 & $0.106 \pm 0.003$ & 22.54 \\
\hline DICLOX & $d$ & 10 & $311 / 160$ & $0.647 \pm 0.030$ & 22.76 & $0.647 \pm 0.052$ & 22.77 \\
\hline
\end{tabular}

${ }^{a}$ Stock solutions used in preparing fortified and MMS samples were 7 days old at the time of the first recovery study, 2 days old at the time of the second recovery study, and 14 days old at the time of the third recovery study. The same stock solutions were used in the second and third recovery studies. ${ }^{b}$ The tolerance for cephapirin + desacetylcephapirin is $100 \mathrm{ng} / \mathrm{g}$. ${ }^{c}$ The tolerance for total desfuroylceftiofur residues in beef kidney tissue is $8000 \mathrm{ng} / \mathrm{g}$. The described LC/MS/MS method detects only DCCD. ${ }^{d}$ Tolerances not established for these analytes.

study (top panel), 2 days old at the time of the second recovery study (middle panel), and 14 days old at the time of the third recovery study (bottom panel). The same stock solutions were used in the second and third recovery studies. Table 6 compares the ratio of the intensities of the two most abundant transitions of each antibiotic, at its established tolerance, in fortified samples and MMS for each of the three recovery studies. For analytes that do not have an established tolerance level, a confirmation ratio at $10 \mathrm{ng} / \mathrm{g}$ is reported. Table 6 shows that the confirmation ratios of the fortified samples are within $20 \%$ of the confirmation ratio of the MMS and thus within the guidelines of confirmation for chemical residue analysis. ${ }^{23-26}$ Table 6 also includes the retention time $\left(t_{\mathrm{R}}\right)$ of each analyte in MMS and fortified samples that are found to be essentially identical within instrumental variation.

(23) Li, L. Y. T.; Campbell, D. A.; Bennett, P. K.; Henion, J. Anal. Chem. 1996, $68,3397-3404$.

(24) Sphon, J. A. I. Assoc. Off. Anal. Chem. 1978, 61, 1247-1253.

(25) Bethem, R.; Boison, J.; Gale, J.; Heller, D.; Lehotay, S. J.; Loo, J.; Musser, S.; Price, P.; Stein S. I. Am. Soc. Mass Spectrom. 2003, 14, 528-541.

(26) André, F.; De Wasch, K.; De Brabander, H. F.; Impens, S. R.; Stolker, L. A. M.; van Ginkel, L.; Stephany, R. W.; Schilt, R.; Courtheyn, D.; Bonnaire, Y.; Fürst, P.; Gowik, P.; Kennedy, G.; Kuhn, T.; Moretain, J,-P. Trends Anal. Chem. 2001, 20, 435-445.

\section{Table 7. Average (\%) and Standard Deviation of Recoveries of $10 \beta$-Lactams in Fortified Control Tissue at 5, 10, 25, 50, 100, 250, 500, and $1000 \mathrm{ng} / \mathrm{g}$ Using Dispersive-SPE Cleanup and LC/MS/MS Analysis ${ }^{a}$}

\begin{tabular}{llcccc}
\multicolumn{1}{c}{ analyte } & first Rec & second Rec & third Rec & av \pm SD & $\begin{array}{c}\text { RSD } \\
(\%)\end{array}$ \\
DECEPH & $79.0 \pm 17.2$ & $69.4 \pm 6.4$ & $67.5 \pm 8.1$ & $72.0 \pm 12.4$ & 17.2 \\
AMOX & $75.6 \pm 7.5$ & $63.9 \pm 3.3$ & $71.1 \pm 7.8$ & $70.0 \pm 8.0$ & 11 \\
DCCD & $56.4 \pm 5.2$ & $56.9 \pm 4.7$ & $61.3 \pm 7.1$ & $58.2 \pm 6.0$ & 10 \\
AMP & $75.1 \pm 4.1$ & $68.9 \pm 3.1$ & $70.5 \pm 4.9$ & $71.5 \pm 4.8$ & 6.7 \\
CFZN & $80.9 \pm 3.6$ & $70.3 \pm 2.5$ & $74.5 \pm 4.4$ & $75.2 \pm 5.7$ & 7.6 \\
PEN G & $78.9 \pm 3.8$ & $71.5 \pm 3.9$ & $73.0 \pm 4.7$ & $74.5 \pm 5.2$ & 7.0 \\
OXA & $79.8 \pm 3.5$ & $72.3 \pm 2.2$ & $72.9 \pm 3.7$ & $75.0 \pm 4.6$ & 6.1 \\
CLOX & $79.5 \pm 3.9$ & $72.1 \pm 2.9$ & $73.7 \pm 4.2$ & $75.1 \pm 4.9$ & 6.5 \\
NAF & $78.5 \pm 4.5$ & $69.3 \pm 1.7$ & $70.8 \pm 5.5$ & $72.9 \pm 5.8$ & 8.0 \\
DICLOX & $79.8 \pm 3.8$ & $65.0 \pm 3.0$ & $69.4 \pm 5.2$ & $71.4 \pm 7.4$ & 10
\end{tabular}

${ }^{a}$ Fortification experiments replicated on three separate days ( $n=$ 24). Stock solutions were 7 days old at the time of the first recovery study, 2 days old at the time of the second recovery study, and 14 days old at the time of the third recovery study.

Table 7 shows the average recoveries (\%) and their associated standard deviations for each of the antibiotics in fortified samples. Fortification experiments were replicated on three separate days 
Table 8. Quantitative LC/MS/MS Analysis and Semiquantitative Microbial Assay Analysis of 30 Incurred Bovine Kidney Tissues ${ }^{a}$

\begin{tabular}{|c|c|c|c|}
\hline \multirow{2}{*}{$\begin{array}{l}\text { incurred } \\
\text { sample }\end{array}$} & \multirow{2}{*}{$\begin{array}{c}\text { tsTD } \\
\text { (weeks) }\end{array}$} & \multicolumn{2}{|c|}{ LC/MS/MS analysis } \\
\hline & & analyte(s) & level (ng/g) \\
\hline $1 \mathrm{~K}$ & 3.5 & PEN G & $86 \pm 6$ \\
\hline \multirow[t]{2}{*}{$2 \mathrm{~K}$} & 3.5 & PEN G & $40 \pm 3$ \\
\hline & & DECEPH & $2.1 \pm 0.4$ \\
\hline $3 \mathrm{~K}$ & 3.5 & PEN G & $114 \pm 13$ \\
\hline $4 \mathrm{~K}$ & 3.5 & DECEPH & $1671 \pm 343$ \\
\hline \multirow[t]{2}{*}{$5 \mathrm{~K}$} & 3.5 & PEN G & $338 \pm 43$ \\
\hline & & DECEPH & $202 \pm 30$ \\
\hline $6 \mathrm{~K}$ & 3.5 & PEN G & $59 \pm 6$ \\
\hline $7 \mathrm{~K}$ & 4 & DCCD & $10400 \pm 1310$ \\
\hline $8 \mathrm{~K}$ & 3.5 & PEN G & $107 \pm 8$ \\
\hline $9 \mathrm{~K}$ & 3.5 & AMP & $139 \pm 11$ \\
\hline $10 \mathrm{~K}$ & 3.5 & PEN G & $205 \pm 17$ \\
\hline $11 \mathrm{~K}$ & 2 & PEN G & $43 \pm 3$ \\
\hline $12 \mathrm{~K}$ & 2 & PEN G & $1037 \pm 72$ \\
\hline $13 \mathrm{~K}$ & 2 & PEN G & $35 \pm 3$ \\
\hline $14 \mathrm{~K}$ & 3 & PEN G & $113 \pm 9$ \\
\hline $15 \mathrm{~K}$ & 3 & AMP & $69 \pm 5$ \\
\hline $16 \mathrm{~K}$ & 3 & PEN G & $15 \pm 2$ \\
\hline $17 \mathrm{~K}$ & 2 & PEN G & $24 \pm 3$ \\
\hline \multirow[t]{2}{*}{$18 \mathrm{~K}$} & 2 & PEN G & $212 \pm 15$ \\
\hline & & DCCD & $112 \pm 16$ \\
\hline $19 \mathrm{~K}$ & 3 & PEN G & $165 \pm 16$ \\
\hline \multirow[t]{2}{*}{$20 \mathrm{~K}$} & 3 & PEN G & $342 \pm 26$ \\
\hline & & DECEPH & $272 \pm 49$ \\
\hline $21 \mathrm{~K}$ & 4 & no analytes & \\
\hline \multirow[t]{2}{*}{$22 \mathrm{~K}$} & 4 & PEN G & $48 \pm 6$ \\
\hline & & DECEPH & $3 \pm 1$ \\
\hline $23 \mathrm{~K}$ & 4 & PEN G & $62 \pm 9$ \\
\hline \multirow[t]{2}{*}{$24 \mathrm{~K}$} & 4 & PEN G & $273 \pm 23$ \\
\hline & & DCCD & $215 \pm 25$ \\
\hline $25 \mathrm{~K}$ & 4 & DCCD & $2250 \pm 246$ \\
\hline $26 \mathrm{~K}$ & 4 & PEN G & $64 \pm 5$ \\
\hline \multirow[t]{2}{*}{$27 \mathrm{~K}$} & 4 & PEN G & $73 \pm 7$ \\
\hline & & DECEPH & $15 \pm 3$ \\
\hline $28 \mathrm{~K}$ & 4 & PEN G & $178 \pm 13$ \\
\hline $29 \mathrm{~K}$ & 4 & PEN G & $608 \pm 58$ \\
\hline $30 \mathrm{~K}$ & 4 & PEN G & $77 \pm 8$ \\
\hline
\end{tabular}

\begin{tabular}{|c|c|}
\hline \multicolumn{2}{|c|}{ 7-plate microbial assay } \\
\hline evaluation & level (ng/g) \\
\hline Pen $(+)$ violative & 110 \\
\hline Pen $(+)$ violative & 70 \\
\hline Pen $(+)$ violative & 140 \\
\hline Pen $(+)$ violative & 120 \\
\hline Pen $(+)$ violative & 530 \\
\hline Pen $(+)$ violative & 100 \\
\hline UMI (DCCD & 12.3 \\
\hline suspected) & $\mathrm{mm}$ \\
\hline Pen $(+)$ violative & 110 \\
\hline $\begin{array}{l}\text { Pen }(+) \text { violative } \\
\text { in kidney }\end{array}$ & 570 \\
\hline Pen $(+)$ in liver & 70 \\
\hline Pen $(+)$ in muscle & 70 \\
\hline Pen $(+)$ violative & 150 \\
\hline Pen $(+)$ violative & 110 \\
\hline Pen $(+)$ violative & 1520 \\
\hline Pen $(+)$ violative & 60 \\
\hline Pen $(+)$ violative & 110 \\
\hline Pen $(+)$ violative & 310 \\
\hline Pen $(+)$ nonviolative & 50 \\
\hline Pen $(+)$ violative & 70 \\
\hline Pen $(+)$ violative & 430 \\
\hline Pen $(+)$ violative & 150 \\
\hline Pen $(+)$ violative & 400 \\
\hline negative & \\
\hline Pen $(+)$ violative & 230 \\
\hline Pen $(+)$ violative & 260 \\
\hline Pen $(+)$ violative. & 460 \\
\hline $\begin{array}{l}\text { also violative for } \\
\text { sulfamethazone } \\
\text { by ELISA }\end{array}$ & \\
\hline Pen $(+)$ violative & 70 \\
\hline Pen $(+)$ violative & 190 \\
\hline Pen $(+)$ violative in kidney & 120 \\
\hline UMI (DCCD suspected) in liver & \\
\hline Pen $(+)$ violative & 330 \\
\hline Pen $(+)$ violative & 1150 \\
\hline Pen $(+)$ violative & 190 \\
\hline
\end{tabular}

${ }^{a}$ tSTD is the age (in weeks) of stock solutions used in preparing matrix-matched standards.

at concentrations of $5,10,25,50,100,250,500$, and $1000 \mathrm{ng} / \mathrm{g}$ to test intraassay ruggedness of the method. No concentration effects were observed; thus, the recoveries were averaged across the entire concentration range $(n=24)$. With the exception of DCCD, analyte recoveries fell within $\sim 70-75 \%$ with relative standard deviations (RSDs) of $<12 \%$ (except for DECEPH, which had $\sim 17 \%$ RSD). DCCD showed the lowest recovery at $\sim 58 \%$, but a reproducibility of $\sim 10 \%$ RSD over multiple days and a wide concentration range demonstrates the consistency of the method. Because DCCD has a reversible disulfide bond between DFC and cysteine, its lower recovery is likely due to the DCCD disulfide bond undergoing exchange with protein thiols or disulfide bonds in the homogenized tissue resulting in the formation of a DFCprotein disulfide complex and, thus, its subsequent loss during the solvent extraction/deproteinization step or its nondetection by conversion to a DFC-peptide disulfide complex not monitored in the present study, e.g., desfuroylceftiofur glutathione disulfide. . $^{19,27-30}$
Confirmation and Quantitation of Incurred Samples. Thirty beef kidney samples suspected of containing violative levels of antibiotics were previously analyzed by the Food Safety and Inspection Service (Midwestern Laboratory, St. Louis, MO) using their approved semiquantitative seven-plate microbial assay. ${ }^{31}$ The microbial assay detects the presence of antibiotics by inhibition of microbial growth on multiple plates. When a tissue extract is deposited onto an agar plate, a circular zone of inhibition will form around the spot where the extract was deposited if the extract contains antimicrobial agents, such as caused by the presence of

(27) Jaglan, P. S.; Cox, B. L.; Arnold, T. S.; Kubrick, M. F.; Stuart, D. J.; Gilbertson, T. J. I. Assoc. Off. Anal. Chem. 1990, 73, 26-30.

(28) Beconi-Barker, M. G.; Roof, R. D.; Millerioux, L.; Kausche, F. M.; Vidmar, T. J.; Smith E. B.; Callahan, J. K.; Hubbard, V. L.; Smith, G. A.; Gilbertson, T. J. L. Chromatogr., B 1995, 673, 231-244.

(29) Fagerquist, C. K.; Hudgins, R. R.; Emmett, M. R.; Håkansson, K.; Marshall, A. G. I. Am. Soc. Mass Spectrom. 2003, 14, 302-310.

(30) Fagerquist, C. K. Rapid Commun. Mass Spectrom. 2004, 18, 685-700.

(31) Payne, M. A.; McBride, M. D.; Utterback, W. W.; Breitmeyer, R. E.; Alberg, L.; Martin, D.; Cullor, J. I. Am. Vet. Med. Assoc. 1999, 214, 1048-1050. 
Table 9. Confirmatory LC/MS/MS Analysis of Incurred Bovine Kidney Tissues Using Matrix-Matched Standards ${ }^{a}$

\begin{tabular}{|c|c|c|c|c|c|c|c|}
\hline \multirow{2}{*}{$\begin{array}{l}\text { incurred } \\
\text { sample }\end{array}$} & \multirow{2}{*}{$\begin{array}{l}\text { analyte } \\
\text { detected }\end{array}$} & \multirow{2}{*}{$\begin{array}{l}\text { fragment } \\
\text { ions }\end{array}$} & \multicolumn{2}{|c|}{ incurred } & \multicolumn{2}{|c|}{ matrix-matched std } & \multirow{2}{*}{$\begin{array}{c}t_{\text {Std }} \\
\text { (weeks) }\end{array}$} \\
\hline & & & ion ratio & $\overline{t_{\mathrm{R}}(\min )}$ & ion ratio & $t_{\mathrm{R}}(\min )$ & \\
\hline $1 \mathrm{~K}$ & PEN G & $176 / 160$ & $0.824 \pm 0.002$ & 20.2 & $0.821 \pm 0.004$ & 20.3 & 3.5 \\
\hline \multirow{2}{*}{$2 \mathrm{~K}$} & PEN G & $176 / 160$ & $0.830 \pm 0.006$ & 20.2 & $0.825 \pm 0.009$ & 20.2 & 3.5 \\
\hline & DECEPH & $112 / 152$ & $0.957 \pm 0.010$ & 10.2 & $0.823 \pm 0.006$ & 10.1 & 3.5 \\
\hline $3 \mathrm{~K}$ & PEN G & $176 / 160$ & $0.819 \pm 0.004$ & 20.2 & $0.814 \pm 0.003$ & 20.3 & 3.5 \\
\hline $4 \mathrm{~K}$ & DECEPH & $112 / 152$ & $0.863 \pm 0.007$ & 10.2 & $0.870 \pm 0.004$ & 10.3 & 3.5 \\
\hline $5 \mathrm{~K}$ & PEN G & $176 / 160$ & $0.819 \pm 0.001$ & 20.2 & $0.821 \pm 0.001$ & 20.3 & 3.5 \\
\hline $6 \mathrm{~K}$ & PEN G & $176 / 160$ & $0.816 \pm 0.002$ & 20.3 & $0.821 \pm 0.004$ & 20.3 & 3.5 \\
\hline $7 \mathrm{~K}$ & $\mathrm{DCCD}$ & $397 / 241$ & $0.435 \pm 0.001$ & 13.0 & $0.434 \pm 0.001$ & 12.9 & 4 \\
\hline $8 \mathrm{~K}$ & PEN G & $176 / 160$ & $0.821 \pm 0.003$ & 20.3 & $0.814 \pm 0.003$ & 20.3 & 3.5 \\
\hline $9 \mathrm{~K}$ & AMP & $192 / 106$ & $0.323 \pm 0.000$ & 13.4 & $0.316 \pm 0.000$ & 13.4 & 3.5 \\
\hline $10 \mathrm{~K}$ & PEN G & $176 / 160$ & $0.816 \pm 0.003$ & 20.3 & $0.814 \pm 0.003$ & 20.3 & 3.5 \\
\hline $11 \mathrm{~K}$ & PEN G & $176 / 160$ & $0.814 \pm 0.007$ & 20.1 & $0.814 \pm 0.011$ & 20.1 & 2 \\
\hline $12 \mathrm{~K}$ & PEN G & $176 / 160$ & $0.833 \pm 0.005$ & 20.1 & $0.817 \pm 0.002$ & 20.1 & 2 \\
\hline $13 \mathrm{~K}$ & PEN G & $176 / 160$ & $0.827 \pm 0.002$ & 20.1 & $0.814 \pm 0.011$ & 20.1 & 2 \\
\hline $15 \mathrm{~K}$ & AMP & $192 / 106$ & $0.318 \pm 0.004$ & 13.3 & $0.319 \pm 0.003$ & 13.3 & 3 \\
\hline $16 \mathrm{~K}$ & PEN G & $176 / 160$ & $0.820 \pm 0.001$ & 20.2 & $0.845 \pm 0.003$ & 20.1 & 3 \\
\hline $17 \mathrm{~K}$ & PEN G & $176 / 160$ & $0.832 \pm 0.001$ & 20.1 & $0.814 \pm 0.011$ & 20.1 & 2 \\
\hline \multirow[t]{2}{*}{$18 \mathrm{~K}$} & PEN G & $176 / 160$ & $0.819 \pm 0.009$ & 20.1 & $0.819 \pm 0.002$ & 20.1 & 2 \\
\hline & DCCD & $397 / 241$ & $0.464 \pm 0.001$ & 12.3 & $0.463 \pm 0.001$ & 12.3 & 2 \\
\hline $19 \mathrm{~K}$ & PEN G & $176 / 160$ & $0.822 \pm 0.001$ & 20.2 & $0.812 \pm 0.004$ & 20.2 & 3 \\
\hline \multirow[t]{2}{*}{$20 \mathrm{~K}$} & PEN G & $176 / 160$ & $0.814 \pm 0.004$ & 20.2 & $0.808 \pm 0.003$ & 20.2 & 3 \\
\hline & DECEPH & $112 / 152$ & $0.857 \pm 0.007$ & 10.2 & $0.842 \pm 0.007$ & 10.1 & \\
\hline $21 \mathrm{~K}$ & no analytes & & & & & & \\
\hline \multirow[t]{2}{*}{$22 \mathrm{~K}$} & PEN G & $176 / 160$ & $0.801 \pm 0.002$ & 20.4 & $0.802 \pm 0.003$ & 20.4 & 4 \\
\hline & DECEPH & $112 / 152$ & $0.779 \pm 0.164$ & 10.5 & $2.678 \pm 0.642$ & 10.4 & 4 \\
\hline $23 \mathrm{~K}$ & PEN G & $176 / 160$ & $0.805 \pm 0.000$ & 20.4 & $0.802 \pm 0.003$ & 20.4 & 4 \\
\hline \multirow[t]{2}{*}{$24 \mathrm{~K}$} & PEN G & $176 / 160$ & $0.795 \pm 0.000$ & 20.4 & $0.802 \pm 0.003$ & 20.4 & 4 \\
\hline & $\mathrm{DCCD}$ & $397 / 241$ & $0.445 \pm 0.000$ & 12.7 & $0.442 \pm 0.001$ & 12.7 & 4 \\
\hline $25 \mathrm{~K}$ & DCCD & $397 / 241$ & $0.440 \pm 0.006$ & 12.8 & $0.443 \pm 0.002$ & 12.7 & 4 \\
\hline $26 \mathrm{~K}$ & PEN G & $176 / 160$ & $0.796 \pm 0.002$ & 20.4 & $0.802 \pm 0.003$ & 20.4 & 4 \\
\hline $28 \mathrm{~K}$ & PEN G & $176 / 160$ & $0.802 \pm 0.002$ & 20.4 & $0.801 \pm 0.005$ & 20.4 & 4 \\
\hline $29 \mathrm{~K}$ & PEN G & $176 / 160$ & $0.806 \pm 0.001$ & 20.4 & $0.808 \pm 0.001$ & 20.4 & 4 \\
\hline $30 \mathrm{~K}$ & PEN G & $176 / 160$ & $0.804 \pm 0.001$ & 20.5 & $0.802 \pm 0.003$ & 20.4 & 4 \\
\hline
\end{tabular}

${ }^{a} t_{\mathrm{R}}$ is the retention time of the analyte. $t_{\mathrm{Std}}$ is the age (in weeks) of stock solutions used in preparing matrix-matches standards.

an antibiotic. The diameter of the zone of inhibition (in $\mathrm{mm}$ ) reflects the amount or strength of the antibiotic present. To correlate zone diameter to antibiotic concentration, a series of dilution standards of PEN G were used to make a calibration curve. PEN G has a tolerance of $50 \mathrm{ng} / \mathrm{g}$. If an unknown sample has a zone of inhibition diameter greater in size than that produced by a $50 \mathrm{ng} / \mathrm{g}$ equivalent PEN G standard, then the sample is considered Pen $(+)$ violative. If the sample has a smaller zone of inhibition, then the sample is considered Pen $(+)$ nonviolative. The PEN G calibration curve can also be used to assign a "concentration" to an unknown sample. However, it should be noted that such a concentration assignment does not constitute a direct measurement of the concentration of the antibiotic but a concentration with respect to the strength of the antimicrobial activity of PEN G. The seven-plate microbial assay was also designed to be able to distinguish between penicillins and cephalosporins. DCCD, DECEPH, and CFZN are cephalosporins whereas the other $\beta$-lactams in this study are penicillins. Detection of a cephalosporin with the seven-plate assay should result in a particular pattern referred to as a "penase" resistant pattern. Penase is an abbreviation for penicillinase: an enzyme produced by bacteria to inactivate penicillins. Cephalosporins are resistant to inactivation by penicillinase and thus are referred to as penase resistant. A sample producing a penase-resistant pattern with the seven-plate assay is designated as an unknown microbial inhibitor (or UMI).

After analysis by the microbial assay, the samples were forwarded to our laboratory for analysis by LC/MS/MS without prior knowledge of the results of the microbial assay. Once the LC/MS/MS analysis was complete, the results of the two analytical techniques were simultaneously exchanged between the two laboratories. Table 8 summarizes the results of both sets of analyses. The percent recoveries of analytes in fortified samples were used to calculate the actual concentrations of analytes in incurred samples. We found general agreement between the LC/ MS/MS analysis and the microbial assay for most of the 30 samples in that there was (1) analytical concurrence with respect to identification of the antibiotic as either a penicillin or a cephalosporin, (2) analytical concurrence with respect to the sample containing violative versus nonviolative levels of an antibiotic, and (3) analytical concurrence (within a factor of $\sim 2-$ 4) with respect to antibiotic concentration. Twenty-three samples fell into this "general agreement" category. A few observations should be made about those samples. First, LC/MS/MS analysis nearly always measured an antibiotic concentration level that was lower than that measured by the microbial assay. The most likely 
reason for this discrepancy was analyte degradation in the sample during the interval between the microbial assay and LC/MS/MS analysis (which were months apart). Analyte degradation in the unhomogenized kidney sample might also explain the analytical dissonance of samples $2 \mathrm{~K}, 11 \mathrm{~K}, 13 \mathrm{~K}, 17 \mathrm{~K}$, and $22 \mathrm{~K}$ that did not fall within the general agreement category because the LC/MS/ MS analysis indicates a nonviolative level of PEN G whereas the microbial assay indicates a Pen $(+)$ violative level of antibiotic. Second, in contrast with LC/MS/MS analysis, the microbial assay cannot specifically identify which antibiotic is present. However, it is interesting to note that the microbial assay does appear to give an approximate estimate of an antibiotic's strength. For instance, the microbial assay of samples $9 \mathrm{~K}$ and $15 \mathrm{~K}$ indicates a Pen (+) antibiotic concentration level that is $\sim 4-5$ times higher than that estimated by LC/MS/MS analysis. LC/MS/MS specifically identifies the antibiotic as AMP as well as quantifying its concentration. AMP is a more powerful antibiotic than PEN G, which is consistent with it having an approved tolerance of 10 $\mathrm{ng} / \mathrm{g}$ whereas PEN G has a tolerance of $50 \mathrm{ng} / \mathrm{g}$. Third, in samples $2 \mathrm{~K}, 5 \mathrm{~K}, 18 \mathrm{~K}, 20 \mathrm{~K}, 22 \mathrm{~K}, 24 \mathrm{~K}$, and $27 \mathrm{~K}$, the presence of a penicillin in a sample (specifically PEN G) appears to mask the presence of the second antibiotic in the microbial assay, specifically a cephalosporin. In contrast, LC/MS/MS analysis not only is able to confirm the presence of these "secondary" antibiotics, it also quantifies the actual amounts of each.

The most serious discrepancy between the microbial assay and the LC/MS/MS analysis occurs for samples $4 \mathrm{~K}$ and $25 \mathrm{~K}$. The microbial assay indicates both samples as Pen $(+)$ violative; however, LC/MS/MS indicates a violative level DECEPH in $4 \mathrm{~K}$ and a possibly violative level of desfuroylceftiofur residues in $25 \mathrm{~K}$. DECEPH and DCCD are cephalosporins, not penicillins. The analysis of these two samples is perplexing because the sevenplate microbial assay was designed to distinguish between penicillins and cephalosporins. For example, the microbial assay identifies sample $7 \mathrm{~K}$ as a UMI (DCCD suspected) with a relatively large zone of inhibition (12.3 mm). LC/MS/MS analysis indicates sample $7 \mathrm{~K}$ as having a violative level of DCCD. Thus, the results of the two analyses are completely concurrent for sample $7 \mathrm{~K}$, and yet for samples $4 \mathrm{~K}$ and $25 \mathrm{~K}$, the results of the two analyses are anomalously dissonant.

Table 9 summarizes the confirmatory analysis of the 30 incurred tissue samples. The MMS that was nearest in concentration to the incurred sample are listed. The confirmatory ion ratios of analytes in incurred samples were within $20 \%$ of the ion ratios of analytes in MMS. ${ }^{23-26}$ In addition, the $t_{\mathrm{R}}$ of analytes in incurred samples are identical, within instrumental variation, to the $t_{\mathrm{R}}$ of analytes in MMS.

Finally, an interesting factor in our quantitative measurements was that the internal standard (PEN V) gave an ion signal intensity that was $10-20 \%$ higher in incurred tissue extracts than in control tissue extracts even though identical amounts of the standard were added to both. The reason for this difference is not certain, but ion suppression effects could be to blame. Furthermore, differences in tissue degradation may have occurred resulting in differences in the contaminant composition of tissue extracts, which may have led to differences in ionization efficiency of the internal standard. This observation notwithstanding, the signal intensities of all analytes were normalized with respect to the signal intensity of the internal standard.

\section{CONCLUSIONS}

We have presented a multiresidue method for the confirmation and quantitation of $10 \beta$-lactam antibiotics in bovine kidney tissue. The method involves simple solvent extraction/deproteinization, dispersive-SPE cleanup, and LC/MS/MS analysis. In contrast to conventional SPE cleanup, dispersive-SPE allowed tripling (or quadrupling) the number of samples prepared in a single day. The method is simple, rapid, rugged, sensitive, and highly specific with recoveries of $70 \%$ (or better) for all the analytes except DCCD for which a recovery of $58 \%$ was obtained. Confirmation and quantitation were achieved at concentrations below tolerance levels for all antibiotics that had an approved tolerance and at 10 $\mathrm{ng} / \mathrm{g}$ for those antibiotics that did not have an approved tolerance. When tested on incurred samples, the method was able to do the following: (i) identify and quantify the antibiotic present in samples that were penicillin $(+)$ by the microbial assay; (ii) identify and quantify the presence of cephalosporin residues in multiresidue samples that were not detected using the microbial assay; and (iii) confirm and quantify only violative levels of cephalosporin residue in samples the microbial assay identified as penicillin $(+)$ violative.

\section{ACKNOWLEDGMENT}

Special thanks are extended to Ralph Wilkinson (FSIS, USDA, St. Louis, MO) for providing incurred bovine kidney tissue as well as results of the microbial assay of these samples. We also thank Rex E. Hornish (Pharmacia, Kalamazoo, MI) for providing samples of DCCD. Thanks also to David N. Heller (Center of Veterinary Medicine, FDA, Laurel, MD) for providing DECEPH. This work was supported by the U.S. Department of Agriculture (CRIS 193542000-044-00D). Mention of a brand or firm name does not constitute an endorsement by the U.S. Department of Agriculture over others of a similar nature not mentioned. This article is a U.S. Government work and is in the public domain in the United States.

Received for review July 19, 2004. Accepted December 3, 2004.

AC040138Q 